obscures et les plus difficiles" (Comptes rendus, t. vi. I 838, pp. 808-812).

This, the first synthetic solution (of General Sabine's address on presenting the Copley Medal) was published, if we mistake not, in I 837 . M. Bertrand, in his éloge of Lamé (January 28, 1878 , Mémoires de l'Académie des Sciences), says"M. Chasles obtenait, en la transportant à la théorie si souvent étudiée de l'attraction des ellipsoïdes, des démonstrations et des résultats admirés comme un modèle d'élégance et de généralité."

We have no space left, having perhaps already dwelt too much in detail upon the complete works, to give an account of the numerous papers we referred to above. This is the less necessary as the results of many are already incorporated in the larger works. We must however just mention the important mechanical principle founded upon the proposition "quand deux polygones égaux sont placés d'une manière quelconque dans un plan, il existe toujours un point du plane qui est également distant de deux sommets homologues quelconques des deux polygones, le point est semblablement placé par rapport aux deux polygones."

The applications of this, under Poncelet's form of enunciation, are fully treated of by Richard in his "Note sur un nouveau principe de cinématique sur son emploi et sur la Théorème de M. Chasles" (Paris, 1856 ).

In the closing lines of the Rapport M. Chasles indignantly condemns the modern system which has for its supreme and immediate object des applications pratiques; and which is " caracterisée suffisamment par l'idée fatale de bifurcation." These remarks we pass over, but gladly draw attention to a wish which he strongly expresses, viz. that a defect should be remedied by the creation of two chairs, one for "Géométrie infinitésimale et analytique," and the other for "Analyse transcendante." If these chairs do not now exist, it would be a fitting compliment to his memory to establish one or both. One other wish we have which we repeat, and that is, following the fashion of the time, that a collected edition of his papers be issued, for at present they are scattered over a very wide area.

In this notice we are indebted to the funeral speeches pronounced over M. Chasles's grave (Comptes rendus, xci. No. xxv., December 20, r880) which, and M. Chasles's own remarks, we have freely cited in their original language, thereby securing conciseness of expression.

We must however linger no longer by the grave, but turn to the "living present," after repeating M. Dumas's last words, "Adieu, Chasles, adieu!" R. TUCKER

\section{PROF. HUXLEY ON EVOLUTION ${ }^{\mathrm{r}}$}

II.

IF all the Mammalia are the results of a process of 1 evolution analogous to that which has taken place in degrees of that process, then a natural classification will arrange them, in the first instance, according to the place which they occupy in the scale of evolution of the mammalian type, or the particular rung of the "scala mammalium " on which they stand. The determination of the position thus occupied by any group may, I think, be effected by the deductive application of the laws of evolution. That is to say, those groups which approach the non-mammalian Vertebrata most closely, present least inequality of development, least suppression, and least coalescence of the fundamental parts of the type, must belong to earlier stages of evolution; while those which exhibit the contrary characters must appertain to later stages.

I Continued from p. 204. By the courtesy of the Secretary of the Zoolological Society we are able to give the remainder of the paper "On the Application of the Laws of Evolution to the Arrangement of the Vertebrata,
and more particularly of the Mammalia," by Prof. T. H. Huxley, F.R.S.
Judged from this point of view, there can be no doubt that the Monotremes embody that type of structure which constitutes the earliest stage of mammalian organisation :- -

r. The mammary glands are devoid of teats; and thus the essential feature of the mammal could hardly be presented under a simpler form.

2. There is a complete and deep cloaca, as in Vertebrata lower in the scale.

3. The openings of the ureters are hypocystic-that is to say, they open, not into the bladder of these animals, but behind it, into the dorsal wall of the genito-urinary passage. As this answers to the neck of the allantois, the ureters of the Monotremes retain their primitive embryonic position.

4. There is no vagina apart from the genito-urinary passage, and the oviducts are not differentiated into distinct uterine and Fallopian regions.

5. The penis and the clitoris are attached to the ventral wall of the cloaca.

6. The epiphyses of the vertebræ are but slightly, or not at all developed. ${ }^{1}$

7. The malleus is relatively very large, and the "processus gracilis," which is singularly long and strong, passes between the tympanic and the periotic bones to the pterygoid, with which it is firmly united. Thus the palato-pterygoid apparatus is directly connected by a "suspensorium" with the periotic, as in the Amphibia and Sauropsida. As in these, the representative of the incus is extremely small and that of the stapes columelliform.

8. The coracoid is complete, distinct, and articulates with the sternum.

9. The hip-girdle is provided with large epipubes, and the iliac axis is inclined at a large angle to the sacral axis.

ro. The corpus callosum is very small.

II. There appears to be no allantoic placenta, though, from the obvious remains of the ductus arteriosus and of the hypogastric arteries, there can be little doubt that the fœtus has a large respiratory allantois. It is quite possible that, with a large umbilical sac, there may be an imperfect "umbilical" placentation.

But, while the Ornithorhynchus and the Echidna are thus the representatives of the lowest stage of the evolution of the Mammalia, I conceive-it to be equally unquestionable that, as Haeckel has already suggested, they are greatly modified forms of that stage-Echidna, on the whole, representing a greater, and Ornithorhynchus a less, departure from the general type. The absence of true teeth in both genera is an obvious sign of extreme modification. The long tongue, extraordinary external auditory passages, and relatively large convoluted brain of Echidna, and the cheek-pouches and horny mouth-plates of Ornithorhynchus, are other indications of the same kind.

Hence, the primary mammals which were less modified, and the existence of which is necessarily postulated in the conception of the evolution of the group, cannot, without risk of confusion, be called Monotremata or Ornithodelphia, since in all probability they were as widely different from Ornithorhynchus and Echidna as the Insectivora are from the Edentata, or the Ungulata from Rhytina. It will therefore be convenient to have a distinct name-Prototheria - for the group which includes these, at present, hypothetical embodiments of that lowest stage of the mammalian type, of which the existing Monotremes are the only known representatives.

A similar reasoning applies to the Marsupialia. In their essential and fundamental characters they occupy an

${ }^{x}$ Dr. Albrecht ("Die Epiphysen und die Amphiomphalie der Säugethierwirbel-körper:" Zoologischer Anzeiger, 1879, No. 18), while admitting that Echidna has no epiphyses, describes epiphyses of an incomplete characte between the posterior twelve caudal vertebræ of Ornithorhynchus. So far as I am aware, the memoir of which Dr. Albrecht has given a preliminary notice, has not yet been published. I content myself therefore with remarking that my own recent observations are in harmony with Dr. Albrecht's statement. 
intermediate position between the Prototheria and the higher mammals.

I. The mammary glands are provided with teats.

2 . The cloaca is so greatly recluced that it is often said to have disappeared.

3. The openings of the ureters are entocystic - that is to say, the ureters open into what is called the "base" of the bladder in front of the narrowed "neck" by which it passes into the tubular "urethra." This means, I conceive, that, morphologically, the bladder of the Marsupial represents the bladder of the Monotreme + the anterior part of the genito-urinary passage; the so-called "trigonum," if not more, of the bladder of the Marsupial, being the homologue of that anterior segment of the genito-urinary passage of the Monotreme.

4. There is a distinct and long vagina, quite separated from the cystic urethra, in the female; and the oviducts are differentiated into uterine and Fallopian portions.

5. The penis is large, and the corpora cavernosa are connected by fibrous tissue and muscles with the pelvis. The spongy body has a large bifurcated bulb, and Cowper's glands are very largely developed.

6. The vertebræ have distinct epiphyses.

7. The malleus is small, and its connections are similar to those which it possesses in the higber mammals. The incus is relatively larger, and the stapes more or less stirrup-shaped.

8. The coracoid is short, does not articulate with the sternum, and becomes ankylosed with the scapula.

9. The hip-girdle is provided with epipubes, usually of large size and well ossified; and the iliac axis is inclined at a small angle to the sacral axis.

Io. The corpus callosum is small.

II. In the few forms of which the fœtus is known there is no allantoic placenta; while the umbilical sac is so large that the possibility of the existence of a transitory umbilical placentation must be taken into account.

It will be observed that in the characters $1,2,3,4,5$, $6,7,8$, and the latter part of the 9 tb, the Marsupials agree with the higher mammals; while in the former part of the 9 th, the Ioth, and the IIth, they present Prototherian characters. So far, therefore, they constitute an intermediate type between that of the Prototheria and that of the higher mammals, which may be termed that of the Metatheria. And if there were any known animals which combined these characters, with a complete double dentition, unmodified pentadactyle manus and pes, and normal uterogestation, they would furnish us the exact transition between the Prototheria and the higher mammals, which must have existed if the law of evolution is trustworthy.

No known Marsupial, however, possesses these additional characters. None has more than a single successional tooth on each side of each jaw; and, as Prof. Flower (to whom we owe the highly important demonstration of this fact) bas pointed out, the question arises whether we have here a primary dentition with only one secondary tooth, or a secondary dentition with only one tooth of the primary set left. I have no doubt that the answer given to this question by Prof. Flower is correct, and that it is the milk-dentition of which only a vestige is left in the Marsupialia. Among existing Rodents, in fact, all conditions of the milk-dentition exist, from a number equal to that of the permanent incisors and premolars (as in the Rabbit ${ }^{x}$ ) to none at all.

The same thing is observed in the Insectivora, where the Hedgehog, and probably Cientetes, have a full set of milk-teeth, while none have yet been found in the Shrews.

I The deciduous molars and the posterior deciduous upper incisors of the Rabbit have been long kncwn. But I have recently found that unborn Rabbits pcssess, in addition, two anterior upper and two lower deciduons incisors. Bcth are simple conical teeth, the sacs of which are merely embedded in the gum. The upper is nct more than one-hundreth of an inch long, the lower rather larger. It would be interesting to examine fœtal Guinea-pigs in relation to this point ; at present they are known to posse:
only the hindmost deciduous molars, so far agreeing with the Marsupials.
In these cases, it is obvious that the milk-dentition has gradually been suppressed in the more modified forms; and I think that there can be no reasonable doubt that the existing Marsupials have undergene a like suppression of the deciduous teeth, in the course of their derivation from ancestors which possessed a full set.

Again, no existing Marsupial possesses an unmodified pentadactyle pes. If the hallux is present, it presents an extensive movement in adduction and abduction; in fact, the pes is prehensile. This is the case in the Phascolomyida, Phalangistida, Phascolarctida, and Didelphida. The Dasyurida present the same type of pes, with the hallux reduced or suppressed. Hence, considering the relations of the Macropodide and the Peramelida with the Phalangers, it seems likely that the hind foot in these groups is also a reduced prehensile pes; in which case this special modification of the foot would characterise the whole of the existing Marsupialia.

Thirdly, the most marked peculiarities of the reproductive organs and processes in the Marsupial are in no wise transitional, but are singularly specialised characters. The suspension of the scrotum in front of the root of the penis is unlike any arrangement in the higher mammals, and the development of the bulb and of Cowper's glands is in excess of anything observable in them. In the female, the cystic urethra is as completely separated from the vagina as it is in the higher mammals while the doubling of the vagina must, in my opinion, also be considered as a special peculiarity which leads from, rather than towards, the higher mammals. In a Monotreme, in fact, the anterior end of the genito-urinary passage exhibits two very short dilatations or cornua, one on each side. In the middle line, a little distance behind these, the ureters open on a prominent ridge-like papilla. The opening of the bladder lies in front of and below the genital cornua. Now, if we compare this arrangement with that which obtains in the lower forms of the higher Mammalia, we find that the ureteric papilla have separated laterally and moved forwards, in such a manner as to occupy the base of the bladder, and the genital cornua come to lie behind and somewhat dorsad of them. At the same time a longitudinal separation has taken place between what may be called the "ureteric" region of the genito-urinary passage and the "genital" region. The first is taken into the bladder and becomes connected by a longer or shorter "cystic urethra" with the latter, which is converted into the longer or shorter vagina. In the Marsupial the same general modification has taken place; but the "genital cornua" become im. mensely elongated, and give rise to the so-called "double" vagina.

Lastly, the marsupium, where it exists, is a no less special feature of the Marsupialia, and, like the peculiarities of the female genital organs, appears to be related with the abnormally early birth of the fœtus. Among the higher Mammalia, it is well known that the fœetus is born in a relatively much earlier state in some cases than in others, even among closely allied species. Thus Rabbits are born hairless and blind, while Hares are born hairy and with their eyes open. I think it probable, from the character of the pes, that the primitive forms, whence the existing Marsupialia have been derived, were arboreal animals; and it is not difficult, I conceive, to see that with such habits it may have been highly advantageous to an animal to get rid of its young from the interior of its body at as early a period of development as possible, and to supply it with nourishment during the Jater periods through the lacteal glands, rather than through an imperfect form of placenta.

However this may be, the characters of the existing Marsupialia leave no doubt on my mind that they are greatly modified members of the metatherial type ; and I suspect that most, if not all, of the Australian forms are of comparatively late origin. I think it probable that the 
great majority of the Metatheria, of which I doubt not a great multitude will shortly be discovered in Mesozoic formations, differed widely from our existing Marsupials ; not only lacking the pouch, as do some existing "Marsupialia," but possessing undivided vaginæ, and probably bringing forth their young, not earlier than existing Carnivores and Rodents do, the nutrition of the foetus during prolonged gestation being provided for, in all probability, by an umbilical placental apparatus, and its respiration by a non-placental allantois.

In the remaining group of the Mammalia, hitherto spoken of as the "higher Mammalia :"-

I. The mammary glands are provided with teats.

2. The cloaca has usually disappeared. Sometimes, however (Beavers, Sloths), a shallow cloaca is present, especially in the female.

3. The openings of the ureters are always entocystic; but their position varies greatly, from close to the neck (e.g. Sorex) to the anterior end of the bladder (e.g. Hyrax).

4. There is a distinct vagina, which is almost always undivided. The oviducts are differentiated into uterine and Fallopian portions.

5. The penis is usually large, the bulb single or partially divided, and the corpora cavernosa almost always directly attached to the ischia.

6. The vertebræ have epiphyses.

7. The malleus is usually small, the incus relatively large, the stapes stirrup-shaped.

8. The coracoid is almost always much reduced, and it is ankylosed with the scapula.

9. The iliac axis makes a small angle with the sacral axis ; and there is no epipubis, or only a fibrous vestige of it.

Io. The corpus callosum and the anterior commissure vary widely. In such forms as Erinaceus and Dasypus they are almost Monotreme-like.

II. The fotus is connected with the uterus of the mother by an allantoic placenta. The umbilical sac varies in size, and in some lower forms (e.g. Lepus) it is, at first, highly vascular, and perhaps plays a quasi-placental part during the early stages of development.

It is obvious that, in all thesc respects, we have the mammalian type in a higher stage of evolution than that presented by the Prototheria and the Metatheria. Hence we may term forms which have reached this stage the Eutheria.

It is a fact, curiously in accordance with what might be expected on evolutionary principles, that while the existing members of the Prototheria and the Metatheria are all extremely modified, there are ccrtain forms of living Eutheria which depart but little from the general type. For example, if Gymnura possessed a diffuse placentation, it would be an excellent representative of an undifferentiated Eutherian. Many years ago, in my lectures at the Royal College of Surgeons, I particularly insisted on the central position of the Insectivora among the higher Mammalia; and further study of this order and of the Rodentia has only strengthened my conviction, that any one who is acquainted with the range of variation of structure in these groups, possesses the key to every peculiarity which is met with in the Primates, the Carnivora, and the Ungulata. Given the common plan of the Insectivora and of the Rodentia, and granting that the modifications of the structure of the limbs, of the brain, and of the alimentary and reproductive viscera, which occur among them, may exist and accumulate elsewhere, and the derivation of all the Eutheria from animals which, except for their simpler placentation, would be Insectivores, is a simple deduction from the law of evolution.

There is no known Monotreme which is not vastly more different from the Prototherian type, and no Marsu-

J The only exception known to me is the Cape Mole (Chrysochloris), which, according to Peters, has none. pial which has not far more widely departed from the Metatherian type, than Gymnura, or, indeed, Erinaceus, have from the Eutherian type.

The broadest physiological distinction between the Prototheria, the Metatheria, and the Eutheria respectively lies in the differences which the arrangements for prolonging the period of intra-uterine and extra-uterine nutrition by the parent present in each. The possibility of a higher differentiation of the species is apparently closely connected with the length of this period. Similarly, the broadest morphological distinction which ean be drawn among the Eutheria lies in their placentation. All forms of deciduate placentation commence by being non-deciduate, and the intimate connection of the fœtal with the maternal structures is subsequent to their loose union. Hence Eutheria, with deciduate placentæ, are in a higher stage of evolution than those with non-deciduate placentæ.

In discussing the relations of the various existing groups of the higher Mammalia with one another, it would be a mistake to attempt to trace any direct genetic connection between them. Each, as the case of the Equidæ suggests, has probably had a peculiar line of ancestry; and, in these lines, Eutherian forms with deciduate placentation constitute the latest term, Eutherian forms with non-deciduate placentation the next latest, Metatherian forms the next, Prototherian forms the carliest among those animals which, according to existing definition, would be regarded as Mammals.

The accompanying Table (p. 230) presents, at a glance, the arrangement of the Mammalia in accordance with the views which I have endeavoured to express. The sign $\mathrm{O}$ marks the places on the scheme which are occupied by known Mammals; while $X$ indicates the groups of which nothing is known, but the former existence of which is deducible from the law of evolution.

I venture to express a confident expectation that investigation into the Mammalian fauna of the Mesozoic epoch will sooner or later fill up these blanks. But if deduction from the law of evolution is to be justified thus far, it may le trusted much farther. If we may confidently expect that Eohippus had a pentadactyle claviculate ancestor, then we may expect, with no less confidence, that the Prototheria proceeded from ancestors which were not mammals; in so far as they had no mammary glands, and in so far as the mandible was articulated with a quadrate bone or cartilage, of which the malleus of the true mammal is the reduced representative. Probably also the corpus callosum had not apfeared as a distinct structure.

Our existing classifications have no place for this "submammalian" stage of evolution (already indicated by Haeckel under the name of Promammale). It would be separated from the Sauropsida by its two condyles, and by the retention of the left as the principal aortic arch; while it would probably be no less differentiated from the Amphibia by the presence of an amnion and the absence of branchia at any period of life. I propose to term the representatives of this stage Hypotheria; and I do not doubt that, when we have a fuller knowledge of the terrestrial Vertebrata of the later palæozoic epochs, forms belonging to this stage will be found among them. Now, if we take away from the Hypotheria the amnion and the corpus callosum, and add the functional branchiæ-the existence of which in the ancestors of the Mammalia is as clearly indicated by their visceral arches and clefts, as the existence of complete clavicles in the ancestral Canidx is indicated by their vestiges in the dog-the Hypotheria, thus reduced, at once take their place among the Amphibia. For the presence of branchiæ implies that of an incompletely divided ventricle and of numerous aortic arches, such as exist in the mammalian embryo, but are more or less completely suppressed in the course of its development. 
Thus I regard the Amphibian type as the representative of the next lower stage of vertebrate evolution; and it is extremely interesting to observe that even the existing Amphibia present us with almost every degree of modification of the type, from such forms as the oviparous, branchiate, small-lunged Siredon and Menobranchus, which stand in the same relation to it as Gymnura to the Eutheria, to the exclusively air-breathing Salamanders and Frogs, in which the period of intraovular development, either within the uterus itself or in special receptacles, may be as much prolonged as it is in the Mammalia.

A careful study, on full materials, of the development of the young of such forms as Hylodes will probably throw great light on the nature of the changes which ended in the suppression of the branchiæ, and the development of the amnion and of the extra-abdominal part of the allantois in the fœetus of the higher Vertebrata.

The recent researches of Boas ${ }^{1}$ on the structure of the heart and the origin of the pulmonary arteries of Ceratodus fell into my hands when I happened to be working afresh at the subject, and had arrived, so far as the heart is concerned, at results which are entirely confirmatory of his. This wonderful creature seems contrived for the illustration of the doctrine of evolution. Equally good arguments might be adduced for the assertion that it is an amphibian or a fish, or both, or neither-the reason of this being that, as it appears to me, Ceratodus is an extraordinarily little modified representative of that particular stage of vertebrate evolution of which both the typical Fishes and the typical Amphibia are special modifications. I think it will be convenient to have a name for the representatives of this stage, and I propose that of Herpetichthyes.

If we were to take away from Ceratodus the membranebones of the heart and the pneumatocœle, and slightly simplify the structure of the heart, the result would be an animal which would undoubtedly be classed among the Chimeroidei; and if, in such a Chimæroid, the lamellar septa of the branchiæ were not reduced, as they are in the Chimaroidei, while the opercular fold remained undeveloped, the product would be a little modified representative of the Selachian group, to which, among actually known forms, Heptanchuus and Cestracion present the nearest approximations. Vertebrated animals in this stage of evolution may be termed Chondrichthyes.

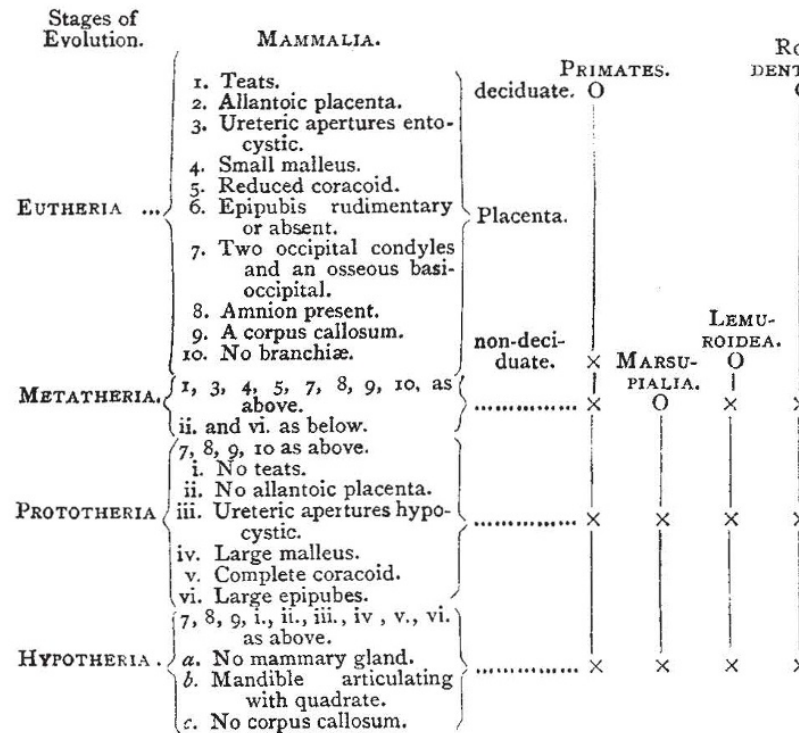

Suppose the limbs and the genital ducts of the Chondrachthyes-stage to be undeveloped, and let the two nasal sacs be represented by a partially divided sac with a single external aperture, the result will be a still lower grade of vertebrate life, which may be termed Myzichthyes, represented only by the greatly modified Lampreys and Hags of the existing fauna.

Finally, let the head retain its primitive segmentation, and the heart its primitive character of a contractile tube, and we reach, in the Hypichthyes, a stage of simplification of the vertebrate type, from which it would be difficult to remove any essential feature without reaching a point at which it is questionable whether an animal should be called "vertebrate." This stage is at present represented only by a singularly modified form, the living Amphioxus.

Thus, in the order of evolution all the Vertebrata hitherto considered may be arranged in nine stages :-I, that of the Hypichthyes; 2, that of the Myzichthyes; 3, that of the Chondrichthyes; 4 , that of the Herpetichthyes; 5 , that of the Amphibia; 6, that of the Hypotheria; 7, that of the Prototheria; 8, that of the Metatheria; and, 9,

I "Ueber Herz und Arterienbogen bei Ceratodus und Protopterus," Merph. Fahrbuch, r880.

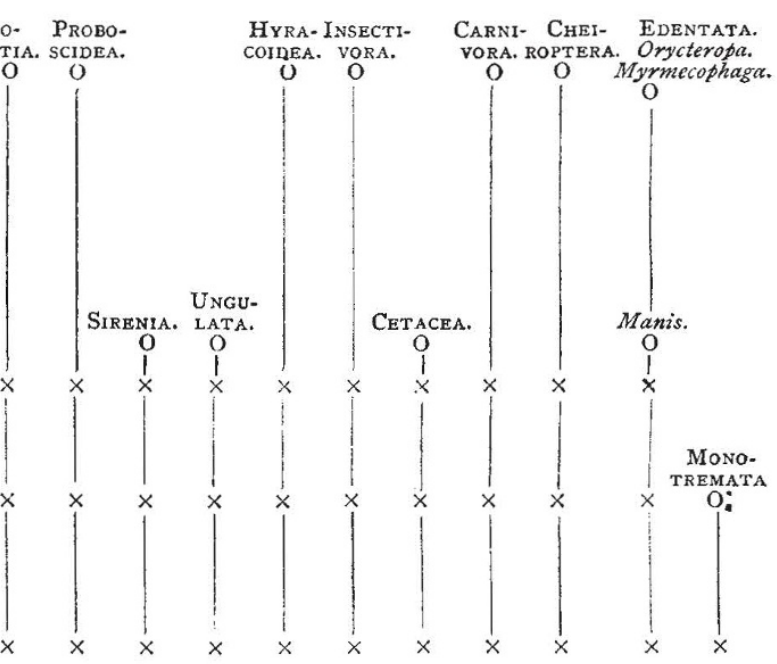

that of the Eutheria. All these stages, except that of the Hypotheria, are represented by existing groups of vertebrated animals, which, in most cases, are composed of greatly modified forms of the type to which they belong, only the Amphibia and the Eutheria exhibiting near approximations to the unmodified type in some of their existing members.

It will be observed that I have omitted to mention the Ganoid and the Teleostean Fishes and the Sauropsida. I have done so because they appear to me to lie off the main line of evolution-to represent, as it were, side tracks starting from certain points of that line. The Ganoidei and the Teleostei I conceive to stand in this relation to the stage of the Herpetichthyes, and the Sauropsida to the stage of the Amphibia.

There is nothing, so far as I can see, in the organization of the Ganoid and Teleostean fishes which is not readily explicable by the application of the law of evolution to the Herpetichthyes. They may be interpreted as effects of the excessive development, reduction, or coalescence of the parts of a Herpetichthyan. ${ }^{1}$

I That the heart of Butirinus affords a complete transition between the characteristically Ganoid and characreristically Teleostean heart, has renant of the supposed hiatus between the Ganoids and the Teleostean vanishes. 
Similarly, the suppression of the branchiæ, the develop. ment of an amnion, and of a respiratory extra-abdominal allantois, and that enlargment of the basioccipital relatively to the exoccipitals which gives rise to a single skull-condyle, is all the change required to convert an Urodele amphibian into a Lizard. It is needless to recapitulate the evidence of the transition from the Reptilian to the Bird type, which the study of extinct animalremains has brought to light.

The scheme of arrangement of the Vertebrata which naturally flows from the considerations now brought forward will stand thus :-

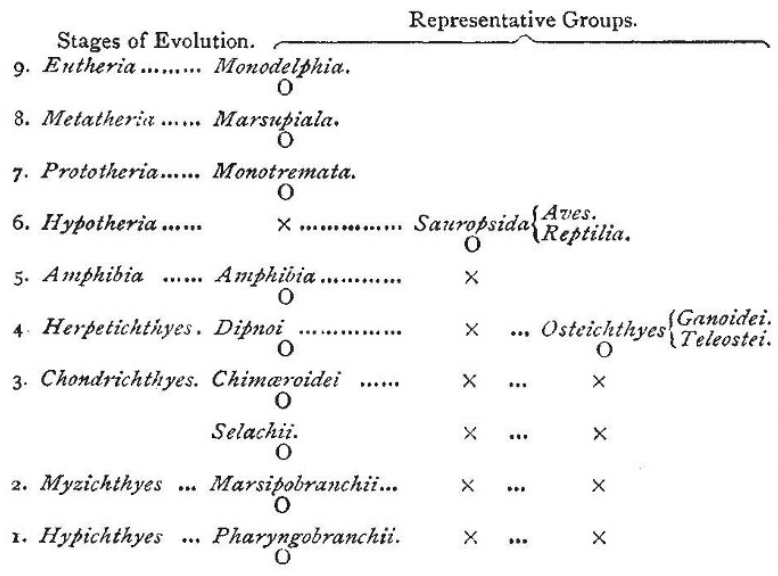

It appears to me that everything which is at present known respecting the Vertebrata of past epochs agrees with the assumption that the law which expresses the process of ancestral evolution of the higher Mammalia is of general application to all the Vertebrata. If this is admitted, I think it necessarily follows that the Vertebrata must have passed successively through the stages here indicated, and that the progress of discovery, while it will obliterate the lines of demarcation between these stages, and convert them into a continuous series of small differentiations, will yield no vertebrate form for which a place does not exist in the general scheme.

\section{NOTES}

DR. John Stenhouse, F.R.S., died on December $3 \mathbf{I}$, in the seventy-second year of kis age. He was a native of Glaigow, where he was educated and long resided. A pupil of Graham and of Liebig, he devoted all his time to research work in the domain of organic chemistry. He was a Royal Medallist of the Royal Society, LL.D. of Aberdeen, and one of the founders of the Chemical Society. On removing to London he was appointed Lecturer on Chemistry in St. Bartholomew's Hospital, London, but was obliged to resign in 1857 , owing to a severe attack of paralysis. This however did not deter him from continuing his scientific studies, which were a labour of love to him. He was the inventor of the cbarcoal respirator, of the charcoal ventilator for sewers, and of a process for rendering fabrics waterproof by means of paraffin. In 1865 he succeeded Dr. Hofmann as non-resident assayer to the Royal Mint, but was deprived of the appointment when the office was abolished by Mr. Lowe in 1870.

ON the 3 rd inst. Mr. John Thomas Towson died at his residence in Liverpool, in his seventy-seventh year. Mr. Towson was connected with the early history of photography, but in I 846 he devoted his tboughts to navigation, especially to determining the quickest routes across the ocean to distant countries. With this object he constructed a set of tables for facilitating the practice of great circle sailing, and at the British Association in $1854 \mathrm{Mr}$. Towson aided Dr. Scoresby in directing the attention of the scientific section to the importance of investigating more fully the subject of the deviation of the compasses on board iron ships. The result of this discussion was the formation of the Liverpool Compass Committee. The observations and the deductions resulting from them were embodied in three reports, "presented to both Houses of Parliament by command of Her Majesty." In $1863 \mathrm{Mr}$. Towson was instructed by the Board of Trade to prepare a manual on the deviation of the compass, which was subsequently published at the expense of the Board, under the title of "Practical Information on the Deviation of the Compass; for the use of Masters and Mates of Iron Ships."

WE are glad to learn that Prof. MacOwan, late of Gill College, Somerset East, has accepted the post of Director of the Botanic Garden, Cape Town. He will also lecture at the South African College. The appointment of a man whose long and enthusiastic devotion to South African botany has earned him a wide reputation is to the credit of the Cape Government, and is of good omen for the scientific future of the Cape Botanic Garden. This has never yet attained the position which it would naturally derive from the resources of one of the most interesting floras in the world.

DR. W. FedDERSEN of Leipzig is preparing a supplement to Poggendorff's well-known biographical dictionary. Many of our readers will receive during the next few days circulars asking them to answer a few questions as to their scientific life and labours. As the great utility of such a work lies in the completeness of the information it supplies, we trust that every one will fill up the answers to the questions as completely as is in his power, and that neither false modesty nor carelessness will create a gap in the work.

Prof. Corfiex.D's lectures on Health to ladies will commence to-day, January 6, by an Introductory Lecture at 3 p.m., and will be continued on Tuesdays and Thursdays at the same hour. Ladies are admitted free to the Introductory Lecture.

Herr Robert Oppenheim of Berlin announces the forthcoming publication of a "Grundriss der Anatomie des Menschen," by Prof. Ad. Pansch of Kiel.

THE Reale Istituto Lombarcho has awarded two sums of 1500 lire, on the Brambilla foundation, ( 1 ) to the Milanese Committee of Animal Vaccination for founding a vaccinogenic establish. ment in Milan ; and (2) to S. Bassolini for establishing in Milan a manufactory of white-lead colours and varnishes. On the Fossati foundation a sum of 2000 lire has been awarded to Dr. Golgi for studies on the fine anatomy of central organs of the nervous system ; and 1000 lire to Drs. Tenchini and Staurenghi for researches in the anatomy of the cerebellum, the Pons Tarini, \&c. A list of prizes now open to competition will be found in the Rendiconti of the Institute, vol. xiii. fasc. xviii. The subjects have nearly all been previously published. (We note that one is "Studies on the Telephane.") The prizes vary in value from 500 to 4000 lire. Foreigners may compete, and memoirs must be written in Italian, French, or Latin.

The Transit of Venus Commission has already met at the French Academy of Sciences, as usual under the presidency of M. Dumas, but no resolution was come to. A number of scientific men have already offered themselves as observers.

BARON NORDENSKjöLd arrived at St. Petersburg on Saturday, and was received at the station by the Swedish Ambassador and delegates from the Russian societies. In the course of the day he was received at the Foreign Office, and is to be fêted by the Municipality and the learned societies. 